Total number of pages: 33

Total number of tables: 6

Total number of figures: 7

\title{
Apparent mass of the human body in the vertical direction: Effect of seat backrest
}

\author{
Martin G.R. Toward, Michael J. Griffin \\ Human Factors Research Unit, Institute of Sound and Vibration Research, \\ University of Southampton, Southampton, SO17 1BJ, England
}

Correspondence address:

Professor Michael J. Griffin

Human Factors Research Unit

Institute of Sound and Vibration Research

University of Southampton

Southampton SO17 1BJ

England

Telephone: (+44) 02380592277

Facsimile: (+44) 02380592927

e-mail: M.J.Griffin@soton.ac.uk 


\section{Abstract}

The transmission of vibration through a seat depends on various characteristics of the seat and the dynamic response of the human body. The dynamic response of the body can be represented by its apparent mass, but the effect of the seat on the apparent mass of the body is not well understood. This study was designed to quantify the effect of foam and rigid backrests on the vertical apparent mass of the human measured at the seat surface supporting the body. The apparent masses of 12 subjects were measured during exposure to random vertical vibration (1.0 $\mathrm{ms}^{-2}$ r.m.s from 0.125 to $40 \mathrm{~Hz}$ ) in a seat with a rigid backrest, in the same rigid seat with three thicknesses of foam backrest $(50,100$ and $150 \mathrm{~mm})$, and in the same seat with no backrest. The backrests were inclined at various angles: $0,5,10,15,20,25$ and 30 degrees for the rigid and 100-mm foam backrests, and 0, 10, 20 and 30 degrees for the 50-mm and 150$\mathrm{mm}$ foam backrests. With all vertical backrests (i.e., 0 degrees inclination), there were resonances in the apparent mass of the body around 5 and $10 \mathrm{~Hz}$. With no backrest, the apparent mass was increased at frequencies less than the resonance frequency but decreased at frequencies between 8 and $20 \mathrm{~Hz}$, relative to the apparent mass with the vertical rigid and foam backrests. With the rigid backrest, the primary resonance frequencies in the apparent mass increased with increasing backrest inclination. With the foam backrests, the resonance frequencies decreased with increasing backrest inclination. At frequencies less than the primary resonance, the apparent mass decreased with increasing backrest inclination, particularly with the rigid backrest. Between 8 and $15 \mathrm{~Hz}$, the apparent mass decreased with increasing inclination, most notably with the foam backrests. At inclinations less than 30 degrees, there was little effect of foam thickness on the apparent mass, but at 30 degrees an increase in the thickness of the foam decreased the frequency of the first resonances. Since contact with backrests and the characteristics of backrests influence the vertical apparent mass of the seated body, backrests should be expected to influence the transmission of vertical vibration through a supporting seat cushion.

Keywords: apparent mass; biodynamics; seats; whole-body vibration; backrests; posture 


\section{Introduction}

The biodynamic responses of the human body provide information on how the body moves and how it will interact with motions causing body movement. For example, the transmission of vibration through a seat is influenced by the dynamic response of the body and not only the dynamic characteristics of the seat (e.g. Refs. [1,2]). Understanding of the biodynamic responses can be used to develop mechanical and mathematical models of the body used to predict seat transmissibility and assist in the optimisation of passenger comfort.

The biodynamic responses of the body have been characterised from measurements of apparent mass, driving point mechanical impedance, and seat-to-head transmissibility. When exposed to vertical vibration, the seated human body exhibits various resonances, the principal of these being around $5 \mathrm{~Hz}$. However, the biodynamic responses of the body are influenced by many factors, especially inter-subject variability (e.g. Refs. $[3,4]$ ), intra-subject variability (e.g. Refs. [3,5]), and the input vibration (due to non-linearities in the response (e.g. Refs. $[3,6,7]$ ). The apparent mass of the human body has often been measured with subjects sitting on a flat rigid seat with no back support (e.g. Refs. [3,4]). Sitting in a car seat involves contact with a backrest, with the backrest varying greatly from one car to another and presenting different contact conditions from those in most laboratory studies of apparent mass.

Some of the mass of a seated body can be supported by a backrest, so even with a rigid vertical backrest the apparent mass at low frequencies can be reduced by a backrest [7]. Some studies have found that the resonance frequency and the apparent mass between 5 and $18 \mathrm{~Hz}$ tend to be increased by a backrest (e.g. Refs. $[7,8])$. When a backrest is reclined, a greater proportion of the body mass is supported by the backrest (approximately $30 \%$ with a backrest reclined to $24^{\circ}$ [9]. Compared with an upright backrest, the resonance frequency, and the apparent mass at frequencies greater than the resonance frequency, have been reported to increase when subjects are supported by a rigid backrest inclined to $12^{\circ}[8]$. With the upperbody supported by a rigid backrest inclined by $24^{\circ}$, the apparent mass normal to the backrest has been reported to have peaks with a magnitude similar to those measured at the seat surface [10]. The apparent masses of subjects supported in an 'automotive posture' (rigid 
backrest inclined by $24^{\circ}$, seat pan inclined by $1^{\circ}$ ) showed peaks between 6.5 and $8.6 \mathrm{~Hz}$, compared to 4.5 to $5.5 \mathrm{~Hz}$ in studies where the back was unsupported or supported by an upright backrest [10]. With subjects fully reclined to the supine position, the dominant resonance frequency in the apparent mass has been reported to reduce from 10.4 to $7.3 \mathrm{~Hz}$ as the vibration magnitude increased from 0.125 to $1.0 \mathrm{~ms}^{-2}$ r.m.s. [11].

Reduced seat transmissibility has been reported at resonance when the back is supported by a foam backrest than when it is supported by a rigid backrest, with the transmissibility at resonance decreasing less when reclining a foam backrest than when reclining a rigid backrest [12]. It seems likely that some of the reported variations in seat transmissibility can be explained by the dynamic properties of seat cushions and variations in the biodynamic responses of the body. The thickness of foam used in a seat has a systematic effect on seat transmissibility and the frequency of the primary seat resonance, consistent with increased hysteretic damping with increased foam thickness [13]. The effect of foam at a backrest on the vertical apparent mass of the body measured at the seat surface has not previously been reported.

The objectives of this study were to investigate the effects of backrest contact, backrest inclination, and backrest foam thickness on the vertical apparent mass measured at the seat surface. It was anticipated that reclining the backrest would reduce the mass supported on the seat surface and, with increased support for the upper-body, the frequency of the primary resonance would increase. It was further hypothesised that the addition of foam to the backrest would reduce the magnitude of the primary resonance in the apparent mass measured at the seat surface, and that the apparent mass at resonance would decrease further with increasing inclination of the backrest as a greater proportion of the mass of the body was supported by the backrest.

\section{Methods and procedures}

\subsection{Apparatus}

The vertical apparent mass of the human body was measured on the surface of a rigid seat with an adjustable backrest. The seat was mounted to a 1-m stroke electro-hydraulic vertical vibrator. Foam squabs of uniform thickness were attached to the backrest of the seat and 
adjustments made so that with 50-mm, 100-mm and 150-mm thick foam backrests and a rigid backrest the subject posture remained unchanged. The dynamic properties of the 100-mm foam had been previously measured using a SIT-bar shaped indenter with a $100-\mathrm{N}$ preload. Over the range of frequencies studied here, the foam stiffness was found to be approximately $21 \mathrm{kN} / \mathrm{m}$ and the damping approximately $109 \mathrm{Ns} / \mathrm{m}$. Subjects sat with their feet supported on a footrest inclined at 35 degrees to the horizontal. The angle of the footrest and its vertical position relative to the seat were chosen to create a posture representative of a car driver. Subjects were instructed to adjust the fore-and-aft position of the footrest to obtain a posture similar to their normal driving posture. A loose lap strap was fastened around the subjects for safety purposes. The general arrangement of the apparatus is illustrated in Fig. 1.

\section{FIG. 1 ABOUT HERE}

The vertical force on the seat surface was measured using a Kistler 9821B force platform consisting of four single-axis piezo-electric force cells located beneath each corner of a top plate. The charge output from the four force cells was summed and conditioned using a Kistler 5001 charge amplifier. An HVLab SIT-pad containing an Entran EGCSDO-10 piezo-resistive accelerometer was used to measure the vertical acceleration on the seat surface.

\subsection{Backrest conditions}

The vertical apparent masses of seated subjects were measured with different backrest conditions to investigate the effects of: (i) an upright rigid backrest and three thicknesses of upright foam backrest (50 mm, $100 \mathrm{~mm}$ and $150 \mathrm{~mm}$ ); (ii) the angle of inclination with rigid and 100-mm thick foam backrests (from 0 to 30 degrees in 5-degree increments); (iii) the angle of inclination with $50 \mathrm{~mm}$ and $150 \mathrm{~mm}$ foam backrests (from 0 to 30 degrees in 10-degree increments). Additionally, the vertical apparent mass of each subject was measured in an upright posture with no backrest contact. In all conditions, the subjects were asked to maintain a relaxed posture without slouching. They placed their hands in their laps and looked straight ahead. 
Subjects were exposed to the 23 conditions in a single session lasting approximately 1 hour. The conditions were presented to subjects in independent random orders to minimize the influence of order effects.

\subsection{Vibration}

The platform was excited using 60 -s periods of Gaussian random vibration at 1.0 ms $^{-2}$ r.m.s. band-limited by 8-pole Butterworth filters between 0.125 and $40 \mathrm{~Hz}$. Over this frequency range the constant bandwidth acceleration spectrum was approximately flat. Signals were generated and analysed using an HVLab data acquisition and analysis system (version 3.81). Different random signals were generated for each subject and equalized for the response of the vibrator. Signals from the force platform and the accelerometer were sampled at 500 samples per second via $167 \mathrm{~Hz}$ anti-aliasing filters.

\subsection{Subjects}

Twelve healthy male subjects (aged 21 to 48 years mean 28.1 years) participated in the study. Their statures ranged between 1.69 and $1.86 \mathrm{~m}$ (mean $1.81 \mathrm{~m}$ ) and their weights between 64 and $93 \mathrm{~kg}$ (mean $74.4 \mathrm{~kg})$.

The experiment was approved by the Human Experimentation, Safety and Ethics Committee of the Institute of Sound and Vibration Research at the University of Southampton.

\subsection{Analysis}

Mass cancellation was performed to remove the influence of the mass of the top-plate of the force platform $(33.0 \mathrm{~kg})$ from the measured force. Mass cancellation was performed in the time domain: the acceleration time-history on the seat surface was multiplied by the mass of the force platform, and then subtracted from the measured force response.

Transfer functions were calculated between the vertical seat acceleration and the vertical force at the seat surface after mass cancellation, to give the apparent masses of the subjects. The apparent mass, $H_{\mathrm{io}}(f)$, was calculated from the cross spectral density between the acceleration and the force at the seat, $G_{i o}(f)$, and the power spectral density of the acceleration at the seat, $G_{\text {ii }}(f)$, using a resolution of $0.195 \mathrm{~Hz}$ : 


$$
H_{\mathrm{io}}(f)=\frac{G_{\mathrm{io}}(f)}{G_{\mathrm{ii}}(f)}
$$

The coherency between the force and acceleration was calculated after mass cancellation in the time domain and found to be greater than 0.9 over the frequency range 0.20 to $30 \mathrm{~Hz}$; above $30 \mathrm{~Hz}$ the coherency tended to decrease slightly but was still generally over 0.8 .

Data analysis was performed using non-parametric statistical methods using SPSS (version 14). Non-parametric tests (Friedman test for $k$-related samples and the Wilcoxon matched-pairs signed ranks test for two-related samples) were employed in the statistical analysis. Nonparametric statistics were used to avoid assuming a normal distribution in the data.

\section{Results}

\subsection{Effect of backrest contact}

The vertical apparent masses of the 12 subjects with no-backrest, with a rigid vertical backrest, and with a vertical $100-\mathrm{mm}$ foam backrest are compared in Fig. 2. With all three backrest conditions, the apparent mass increased to a peak around $5 \mathrm{~Hz}$ and decreased at higher frequencies. Some subjects exhibited a second resonance, with the frequency varying between subjects over the range 7 to $14 \mathrm{~Hz}$. At frequencies between 15 and $40 \mathrm{~Hz}$ there was no evidence of major resonances of the body. The phase lag between the vertical acceleration and the vertical force increased to 1.5 radians around the resonance and then remained approximately constant to higher frequencies. For some subjects the phase response decreased or increased slightly from 15 to $40 \mathrm{~Hz}$. The phase can be very much influenced by imperfect mass cancellation - the response at $40 \mathrm{~Hz}$ may have been influenced by small errors in the mass cancellation for some subjects. The median apparent masses for these three conditions are shown in Fig. 3.

\section{FIGURES 2 AND 3 ABOUT HERE}

The medians of the resonance frequencies of the 12 subjects with each of the 23 backrest conditions are given in Table 1 and the medians of the individual apparent masses at each subject's resonance frequency are shown in Table 2. There was no significant difference 
between no-backrest, a vertical rigid backrest, and a vertical 100-mm foam backrest in either the frequency of the primary resonance or the apparent mass at resonance $(p=0.12$ and $p=$ 0.17 , respectively; Friedman).

\section{TABLES 1 AND 2 ABOUT HERE}

Further statistical analysis was conducted to investigate whether backrest contact affected the proportion of the subject mass supported on the seat surface. At very low frequencies the measured apparent mass of a subject is approximately equal to the static mass supported on the seat surface, because the body is almost rigid. Significant differences in apparent mass were found between the three backrest conditions (no-backrest, a vertical rigid backrest, and a vertical $100-\mathrm{mm}$ foam backrest) at $0.4 \mathrm{~Hz}$ (Friedman, $p=0.01$ ). The apparent mass at $0.4 \mathrm{~Hz}$ reduced by approximately $10 \mathrm{~kg}$ with a rigid and a foam backrest compared to no-backrest $(p<$ 0.01 ; Wilcoxon). There was no significant difference in the mass supported on the seat surface with the rigid and the foam backrests $(p=0.35)$.

At frequencies between 7 and $15 \mathrm{~Hz}$, the apparent mass in the three conditions was influenced by the backrest (Friedman, $p<0.01$ ). The apparent mass increased when there was contact with the rigid backrest compared to no-backrest (at $12 \mathrm{~Hz}, p=0.02$; Wilcoxon), and between the foam backrest and the no-backrest conditions ( $p=0.01$; Wilcoxon). There was no significant difference in apparent mass between the no-backrest and the foam backrest conditions $(p=$ $0.27)$.

A comparison of apparent masses at $40 \mathrm{~Hz}$ produced significant differences between pairs of conditions similar to those at $12 \mathrm{~Hz}$. The influences of other backrest variables (angle, foam thickness) on apparent mass were also statistically significant at $40 \mathrm{~Hz}$ if they were significant at $12 \mathrm{~Hz}$. Consequently, subsequent figures and analysis are only presented for frequencies less than $20 \mathrm{~Hz}$.

\subsection{Effect of inclination of the rigid backrest}

The median apparent masses of the 12 subjects measured with each inclination of the rigid backrest are shown in Fig. 4. The frequency of the primary resonance tended to increase as the backrest was reclined from $0^{\circ}$ to $25^{\circ}$, although only when the backrest was reclined to $15^{\circ}$ and 
$20^{\circ}$ was the resonance frequency significantly greater than with the upright backrest $(p<0.05)$. The resonance frequency with the backrest inclined to $30^{\circ}$ was significantly greater than when the backrest was inclined to $0,5,10$ and $25^{\circ}(p<0.05)$ but was not significantly greater than with $15^{\circ}$ and $20^{\circ}$ inclination $(p>0.05$, Table 3$)$.

\section{FIG. 4 AND TABLE 3 ABOUT HERE}

At frequencies less than $8 \mathrm{~Hz}$, the apparent mass tended to reduce as the backrest was reclined. A similar but lesser effect is apparent between 10 and $15 \mathrm{~Hz}$. At frequencies greater than $15 \mathrm{~Hz}$, the apparent mass was unaffected by backrest inclination. The apparent mass at the primary resonance tended to decrease with increasing backrest inclination, with significant differences between 14 of the 21 pairs of backrest inclinations $(p<0.05$; Table 3$)$.

The median 'static mass' supported on the platform (i.e. the apparent mass at $0.4 \mathrm{~Hz}$ ) decreased from $51.7 \mathrm{~kg}$ to $43.9 \mathrm{~kg}$ as the backrest was reclined from $0^{\circ}$ to $30^{\circ}$. The apparent mass at $0.4 \mathrm{~Hz}$ was unaffected by variations in backrest inclinations up to $15^{\circ}$, but was significantly reduced with the backrest inclined at 20,25 , and $30^{\circ}(p<0.05$; Table 3$)$.

\subsection{Effect of inclination of the 100-mm foam backrest}

Fig. 5 shows the effect of reclining the $100-\mathrm{mm}$ foam backrest on the median apparent mass; statistical analysis is given in Table 4. With inclinations greater than $5^{\circ}$, the resonance frequency tended to decrease with increasing backrest angle. This differs from the effect of reclining the rigid backrest where the resonance frequency tended to increase with increasing backrest inclination. There were significant differences between the resonance frequencies with 14 of the 21 backrest pairs $(p<0.05)$. However, the resonance frequencies with the backrest reclined to 5,10 , and $15^{\circ}(p>0.05)$ did not differ from that with the upright backrest.

\section{FIG. 5 AND TABLE 4 ABOUT HERE}

The static mass supported on the seat surface (the apparent mass at $0.4 \mathrm{~Hz}$ ) was unaffected by inclinations of the $100-\mathrm{mm}$ foam backrest up to $25^{\circ}$ ( $p>0.05$; Friedman). As the inclination increased from $25^{\circ}$ to $30^{\circ}$, the apparent mass reduced from $51.7 \mathrm{~kg}$ to $48.8 \mathrm{~kg}$. There were statistically significant differences in the apparent mass at $0.4 \mathrm{~Hz}$ between $5^{\circ}$ and $30^{\circ}$, between 
$15^{\circ}$ and $30^{\circ}$, and between $20^{\circ}$ and $30^{\circ}(p<0.05)$. Similarly, the apparent mass at resonance was broadly unchanged with backrest angles up to $25^{\circ}$ but decreased at $30^{\circ}$. The apparent mass between 8 and $20 \mathrm{~Hz}$ tended to decrease with increasing backrest inclination, with significant differences between 15 of the 21 pairs of backrest inclinations for the response at 12 $\mathrm{Hz}(p<0.05)$.

\subsection{Effect of backrest foam thickness at different backrest inclinations}

The effect on apparent mass of increasing the thickness of the foam on the backrest at different angles of backrest inclination is shown in Fig. 6 . With the upright backrest, the apparent masses with the three foam thicknesses were similar at frequencies less than $8 \mathrm{~Hz}$, with no significant differences in either the apparent mass at $0.4 \mathrm{~Hz}$ or the apparent mass at resonance $(p>0.1$, Friedman). At frequencies between 8 and $20 \mathrm{~Hz}$, the rigid backrest resulted in slightly greater apparent mass compared to the foam backrests. There were significant differences in apparent mass between the rigid backrest and the three thicknesses of foam backrest at $12 \mathrm{~Hz}$, but no significant difference in apparent mass between the three foam backrests at this frequency.

\section{FIG. 6 AND TABLE 5 ABOUT HERE}

With the backrest inclined to 10 degrees, the apparent mass was unaffected by the thickness of the three foam backrests, but the apparent mass was greater with the rigid backrest at frequencies between 7 and $30 \mathrm{~Hz}(p<0.05$ at $12 \mathrm{~Hz})$.

With the backrest inclined to $20^{\circ}$, a difference between the rigid backrest and the three thicknesses of foam backrest was more evident. With the rigid backrest, the apparent mass was reduced at frequencies less than $8 \mathrm{~Hz}$ but increased at higher frequencies than with the three foam backrests. There were significant differences in the apparent mass between the rigid backrest and all three thicknesses of foam backrest at resonance and at $12 \mathrm{~Hz}$. At $0.4 \mathrm{~Hz}$ there were significant differences in the apparent mass between the rigid and the two thicker foam backrests $(p<0.05)$ and also between the $50 \mathrm{~mm}$ foam backrest and the other two foam backrests $(p<0.05)$. The resonance frequency of the apparent mass was significantly higher with the rigid backrest than with each of the three thickness of foam backrest $(p<0.05)$. 
With the backrest inclined to $30^{\circ}$, the apparent mass with the $50-\mathrm{mm}$ foam backrest was lower at $0.4 \mathrm{~Hz}$ and higher at $12 \mathrm{~Hz}$ compared to the apparent mass with the $100-\mathrm{mm}$ and $150-\mathrm{mm}$ foam backrests $(p<0.05)$. The apparent mass resonance frequency with the rigid backrest, was $6.35 \mathrm{~Hz}$, and significantly higher than with the $150-\mathrm{mm}$ foam backrest, at $4.20 \mathrm{~Hz}(p<0.01)$. The resonance frequency was also higher with the $50-\mathrm{mm}$ foam backrest than with the other two thicker backrests $(p<0.05$; Table 1$)$.

\subsection{Effect of backrest angle with different thicknesses of foam backrest}

The effect of backrest angle on apparent mass with the rigid backrest and the three thicknesses of foam backrest is shown in Fig. 7. At low frequencies (i.e., $<1 \mathrm{~Hz}$ ) and at resonance there is a small but consistent reduction in the apparent mass as the backrest angle increases with the rigid backrest, but this is less noticeable with the foam backrests. This was borne out in the statistical analysis which showed that, at $0.4 \mathrm{~Hz}$ and at resonance, the number of significant differences between apparent masses at pairs of backrest angles was less for each of the foam backrests than the rigid backrest (Table 6). From 8 to $20 \mathrm{~Hz}$, the variation in apparent mass with backrest inclination tended to increase with increasing foam thickness, with the apparent mass generally decreasing as the backrest was reclined. At $12 \mathrm{~Hz}$, the differences in apparent mass were significant between five of the six backrest angle pairs for both the 100-mm and the 150-mm foam backrests compared to only three of the six for the rigid backrest.

\section{FIG. 7 AND TABLE 6 ABOUT HERE}

With the rigid backrest, as the backrest angle increased the frequency of the first resonance increased. With the foam backrests, the resonance frequency tended to decrease as the backrest angle increased. Statistical analysis shows that this effect was more pronounced with greater thickness of foam (Table 5).

With the 50-mm foam backrest, the greatest apparent mass at resonance occurred when the backrest was reclined to $10^{\circ}$ and the lowest apparent mass at resonance occurred when the backrest was reclined to $30^{\circ}$ (Table 2). A similar trend occurred with the $100-\mathrm{mm}$ and $150-\mathrm{mm}$ foam backrests, except that the greatest apparent mass at resonance occurred when the seat was reclined to $15^{\circ}$ and $20^{\circ}$, respectively. 


\section{Discussion}

\subsection{Effect of backrest contact}

The moduli and phases of the vertical apparent masses of the subjects with no backrest contact were similar to those previously reported (e.g. Refs. $[3,14,15)$. Subjects showed a principal resonance in the $5-\mathrm{Hz}$ region and some subjects showed a second resonance in the 7 to $14 \mathrm{~Hz}$ range.

Contact with the rigid vertical backrest generally decreased the apparent mass at frequencies less than the resonance frequency and increased the apparent mass in the frequency range 7 to $14 \mathrm{~Hz}$, consistent with the findings of Fairley and Griffin [3] and Nawayseh and Griffin [16]. Although Wang et al. [8] found a similar increase in the apparent mass at frequencies greater than the primary resonance with an upright backrest, they found the apparent mass at frequencies less than the resonance frequency was largely unaffected by backrest contact, contrary to the findings of this study. Although the seat heights differed between the studies ( $0.34 \mathrm{~m}$ above the foot support in this study and $0.46 \mathrm{~m}$ in the previous study), this is unlikely to explain the difference: Nawayseh and Griffin [7] found that backrest contact decreased the apparent mass at frequencies less than the resonance frequency irrespective of the height of the feet relative to the seat surface. The increase in the apparent mass between 7 and $14 \mathrm{~Hz}$ with backrest contact is consistent with an increase in damping of the primary resonance.

There was a small but statistically significant increase in the resonance frequency when subjects were supported by a rigid backrest compared to no backrest. This is consistent with Nawayseh and Griffin [7] but contrary to Nawayseh and Griffin [16] and the findings of Wang et al. [8] in which there were no significant effects of a rigid backrest on the resonance frequency. The difference might be explained by the backrest employed: in this study and the earlier study by Nawayseh and Griffin [7] the lumbar spine and pelvis were not in contact with the backrest whereas in the later study by Nawayseh and Griffin [16] and the study by Wang et al. [8] there was contact with the full length of the back. Previous studies (e.g. Ref. [3]) have found that when subjects vary between an 'erect' and 'tensed' posture there is a corresponding change in their apparent mass resonance frequency. Where the lumbar region was not supported, the 
subjects may have exerted greater muscle tension or maintained a more upright posture than with no backrest or a full backrest support, resulting in an increased resonance frequency. In this study the apparent mass at $0.4 \mathrm{~Hz}$ decreased by approximately $10 \mathrm{~kg}$ when there was contact with a rigid flat vertical backrest. This indicates that either this was supported by the backrest or the feet supported a greater proportion of the body weight when this backrest was present. Nawayseh and Griffin [15] measured the vertical apparent mass at both the seat and the backrest and found that when subjects were in contact with an upright backrest the apparent mass at the seat was reduced at low frequencies, consistent with the findings of this study. They also found that the vertical forces on a seat with no backrest were the same as the vector addition of the vertical forces at the seat surface and the backrest. This indicates that a proportion of subject body weight was supported by shear forces at the backrest.

With the 100-mm foam backrest, the apparent mass at frequencies less than the resonance frequency was similar to that with the rigid backrest, indicating that at low frequencies a similar proportion of subject mass was supported in shear by the $100-\mathrm{mm}$ foam backrest and the rigid backrest. At frequencies between $7 \mathrm{~Hz}$ and $15 \mathrm{~Hz}$, the apparent mass was lower with the foam backrest than with no backrest, possibly due to the second resonance being less evident in some subjects when there was no backrest. The origin of the second resonance is not certain, but a biodynamic model developed by Matsumoto and Griffin [17] indicated that the resonance could be caused by a rotational mode of the pelvis and the lower upper-body. This mode may have been more damped by the foam backrest than the rigid backrest.

\subsection{Effect of backrest inclination}

The resonance frequency in the vertical apparent mass at the seat surface increased from $5.47 \mathrm{~Hz}$ with a vertical rigid backrest to $6.35 \mathrm{~Hz}$ when this backrest was reclined to $30^{\circ}$. Rakheja et al. [10] measured the vertical apparent mass on the surface of a seat with a backrest reclined to $24^{\circ}$ and found the mean resonance of the subjects at $7.8 \mathrm{~Hz}$. The present study used an input magnitude of $1.0 \mathrm{~ms}^{-2}$ r.m.s. whereas Rakhekja et al. [10] used $0.5 \mathrm{~ms}^{-2}$ r.m.s over a similar frequency range $(0.5$ to $40 \mathrm{~Hz})$. It is has been widely reported that the response of the body is non-linear with input magnitude: the resonance frequency decreasing with increasing 
vibration magnitude (e.g. Ref. [6]). The differences in resonance frequency between the two studies may be a result of the different excitation magnitudes. There were also postural differences between the two studies: in this experiment a flat rigid seat pan was used but Rakheja et al. [10] employed a seat pan inclined to $13^{\circ}$. However, both Nawayseh and Griffin [16] and Wang et al. [8] have found that the inclination of a seat pan had a negligible effect on the vertical apparent mass. The resonance frequency of the apparent mass of the body (not legs) of supine subjects measured with an input magnitude of $1.0 \mathrm{~ms}^{-2}$ r.m.s., as in this study, has been reported as $7.32 \mathrm{~Hz}$ (e.g. Ref. [11]). This is higher than the resonance frequencies measured in this study and consistent with increased resonance frequency with increased inclination. The findings of these studies suggest that the changes in the apparent mass of the body caused by contact with an inclined rigid backrest may be reflected by increasing the stiffness in an apparent mass model, although the actual changes in the body will be more complex. This increase in stiffness could be a result of the rigid backrest constraining the motions of the upper body. At higher backrest inclinations, more mass of the body is supported on the backrest this may further constrain the motions of the upper body.

With no backrest, excitation of the body occurs primarily through the supporting seat surface. When subjects are also supported by a backrest, there is an additional source of excitation, which is in the $z$-axis of the back when the backrest is vertical but increasingly in the $x$-axis of the back as the backrest is reclined. The two inputs will be in-phase with a rigid seat but there will be phase differences between the inputs when either the backrest or the seat surface are not rigid. Clearly, the dynamic response of the body under these circumstances is not simple, although it may be possible to provide simple representations of the apparent mass of the body that are sufficient to assist the optimisation of the dynamic responses of seats.

The apparent mass resonance frequency and also the response between 5 and $15 \mathrm{~Hz}$ tended to decrease as the foam backrests were reclined; this is consistent with a decrease in the 'stiffness' of the combined response of the body and the backrest. This decrease in stiffness might be explained by the foam being more compliant when there was more of the subject's weight supported normal to the backrest and consequently greater compression forces acting on the foam. That this decrease became more pronounced as the thickness of foam increased, 
is consistent with the compressive stiffness of the foam decreasing as the thickness was increased.

The apparent mass reduced at low frequencies as the rigid backrest and the $50-\mathrm{mm}$ foam backrest were reclined, indicating that a reduced proportion of the subject body mass was supported on the seat surface. With the $100-\mathrm{mm}$ and $150-\mathrm{mm}$ foam backrests, the static mass supported on the seat surface increased as the backrest was reclined from $0^{\circ}$ to $10^{\circ}$ but then decreased as the backrest was reclined from $10^{\circ}$ to $30^{\circ}$. At $30^{\circ}$, the static mass on the seat surface with the rigid backrest was $43.9 \mathrm{~kg}$, while the median static mass at this inclination with the foam backrests varied between 47.0 and $48.7 \mathrm{~kg}$. The difference in static mass supported on the seat surface between the reclined rigid and reclined foam backrests might be explained by postural differences. With the reclined rigid backrest, subjects were likely to maintain a straight back whereas with the foam backrests subjects may have adopted a kyphotic posture in which the centre of gravity was brought forward, reducing the mass supported on the backrest.

\subsection{Effect of the thickness of foam on the backrest}

The thickness of foam on the backrest had the greatest effect on the measured apparent mass when the backrest was inclined to $30^{\circ}$, with the resonance frequency decreasing with increasing thickness of foam, consistent with a lowering of the stiffness of the body-backrest system.

There was evidence of increased damping of the primary resonance in the apparent mass (a broadening of the resonance peak with increased apparent mass at frequencies greater than the resonance frequency) with the foam backrest compared to the rigid backrest. However, there was no evidence in the apparent mass of further increases in damping with increasing foam thickness. The mass supported on the seat surface increased with increasing thickness of foam, consistent with the thicker foam being more compliant and supporting less of the subject weight on the backrest.

4.4 Implications for seat testing and biodynamic models

This study shows that contact with a backrest, and the inclination and compliance of a backrest, influence the vertical apparent mass of the human body measured at a seat surface. As the vibration transmitted through a seat is dependent on the apparent mass of the body, contact 
with a backrest and the inclination and compliance of a backrest will also affect seat transmissibility (e.g. Ref. [12]). When measuring seat transmissibility it therefore seems advisable to use an appropriate backrest set to an angle appropriate for the vehicle, or to measure seat transmissibility with a range of backrest inclinations.

Biodynamic models of the dynamic responses of the body have not generally been developed to consider interactions with a backrest (e.g. Refs. $[17,18])$. Wei and Griffin [18] showed that a simple two-degree of freedom model could accurately reflect the apparent mass of subject sitting upright with no backrest contact. This model was combined with measurements of the dynamic stiffness and damping of foam to provide useful predictions of seat transmissibility for subjects sitting with no backrest [19]. The principal effect of contact with a backrest in the current study was a shifting of the resonances in the apparent mass as opposed to the addition of new resonances. This suggests it may be appropriate for the effect of backrest contact on the apparent mass at the seat surface to be approximated by adjustments to the parameters of a two degree-of-freedom model (e.g. Ref. [18]). Different types and inclinations of backrest might be represented by different values for the variables within the model. An alternative to this approach is to include backrest interaction within a mechanistic model. The vertical transmissibility of a car seat with subjects supported by a backrest reclined to $20^{\circ}$ can be represented by a four degree-of-freedom lumped parameter model with vertical stiffness and damping elements representing the total compliance of the back and the backrest [20]. This model did not attempt to separate out the compliance of the backrest or the reflect effects of backrest inclination. To represent these factors, a mechanistic model requires rotational or cross-axis components. It has been found that a three degree-of-freedom model with vertical, fore-and-aft and rotational (i.e., pitch) degrees-of-freedom can be optimised to represent the vertical apparent mass and the fore-and-aft cross-axis apparent mass of the human body with no backrest support [21]. The dynamic properties of a reclined compliant backrest has been taken into account in a nine degree-of-freedom model representing the transmission of vertical vibration to the hip and head and also the fore-aft transmissibility to the back, with the human body represented by three rigid bodies connected by rotational spring and damper elements 
[22]. A similar model could represent the dynamic response of the body and the backrests in the conditions investigated in this study.

\section{Conclusions}

Contact with an upright rigid backrest or upright foam backrests reduces the body mass supported on the seat surface, indicating backrests support a proportion of the body mass in shear. Reclining a backrest reduces the proportion of subject mass supported on the seat surface, although the reduction is less apparent when compliance of foam in a backrest reduces the proportion of the body mass supported by the backrest.

The apparent mass resonance frequency is little affected by contact with either a vertical flat rigid backrest or a vertical foam backrest. Whereas reclining a rigid backrest increases the resonance frequency, reclining a foam backrest decreases the resonance frequency: with a backrest inclined to $30^{\circ}$, the resonance frequency was $6.35 \mathrm{~Hz}$ with a rigid backrest compared to $4.49 \mathrm{~Hz}$ with a $100-\mathrm{mm}$ foam backrest.

The thickness of foam on the backrest had the greatest effect on the vertical apparent mass measured at the seat when the backrest was maximally inclined to 30 degrees, with the resonance frequency and the apparent mass between 5 and $15 \mathrm{~Hz}$ greater, and the mass supported on the seat less, with $50-\mathrm{mm}$ foam than with $100-\mathrm{mm}$ and $150-\mathrm{mm}$ foam. 


\section{References}

[1] C. Corbridge, M.J. Griffin, P. Harborough, Seat dynamics and passenger comfort. Institute of Mechanical Engineers, Part F: Journal of Rail and Rapid Transit 203 (1989) 57-64.

[2] T.E. Fairley, M.J. Griffin, A test method for the prediction of seat transmissibility. Society of Automotive Engineers International Congress and Exposition, Detroit, February 24-28, SAE Paper 860046, 1986.

[3] T.E. Fairley, M.J. Griffin, The apparent mass of the seated human body: vertical vibration. Journal of Biomechanics 22 (1989) 81-94.

[4] P. Holmlund, R. Lundström, L. Lindberg, Mechanical impedance of the human body in vertical direction. Applied Ergonomics 31 (2000) 415-422.

[5] N.J. Mansfield, M.J. Griffin, Effects of posture and vibration magnitude on apparent mass and pelvis rotation during exposure to whole-body vertical vibration. Journal of Sound and Vibration 253 (1) (2002) 93-107.

[6] Y. Matsumoto and M.J. Griffin, Non-linear characteristics in the dynamic responses of seated subjects exposed to vertical whole-body vibration, Journal of Biomechanical Engineering 124 (2002) 527-532.

[7] N. Nawayseh, M.J. Griffin. Tri-axial forces at the seat and backrest during whole-body vertical vibration. Journal of Sound and Vibration 277 (2004) 309-326.

[8] W. Wang, S. Rakheja, P.É. Boileau, Effects of sitting postures on biodynamic response of seated occupant under vertical vibration. International Journal of Industrial Ergonomics 34 (2004) 289-306.

[9] S. Rakheja, I. Stiharu, P.É. Boileau, Seated occupant interactions with seat backrest and pan, and biodynamic response under vertical vibration. Journal of Sound and Vibration 298 (1) (2006) 651-671.

[10] S. Rakheja, I. Stiharu, P.É. Boileau, Seated occupant apparent mass characteristics under automotive posture and vertical vibration. Journal of Sound and Vibration 253 (1) (2002) 57-75. 
[11] Y. Huang, M.J. Griffin, Nonlinear dual-axis biodynamic response of the semi-supine human body during vertical whole-body vibration. Journal of Sound and Vibration, 312 (1-2) (2008) 296315.

[12] M.G.R. Toward, Effect of backrest inclination on seat cushion transmissibility. Proceeding of the 36th U.K. Group Meeting on Human Response to Vibration, QinetiQ Ltd, Farnborough, England, 12-14 September (2001) 106-115.

[13] K. Ebe, M.J. Griffin, Qualitative models of seat discomfort including static and dynamic factors. Ergonomics 43 (6) (2000) 771-790.

[14] N.J. Mansfield, M.J. Griffin, Non-linearities in apparent mass and transmissibility during exposure to whole-body vertical vibration. Journal of Biomechanics 33 (2000) 933-941.

[15] N. Nawayseh, M.J. Griffin, Non-linear dual-axis biodynamic response to vertical whole-body vibration. Journal of Sound and Vibration 268 (2003) 503-523.

[16] N. Nawayseh, M.J. Griffin, Effect of seat surface angle on forces at the seat surface during whole-body vertical vibration. Journal of Sound and Vibration 284 (2005) 613-634.

[17] Y. Matsumoto, M.J. Griffin, Modelling the dynamic mechanisms associated with the principal resonance of the seated human body. Clinical Biomechanics 16 (2001) 31-44.

[18] L. Wei, M.J. Griffin, Mathematical models for the apparent mass of the seated body exposed to vertical vibration. Journal of Sound and Vibration 212 (1998) 855-874.

[19] L. Wei, M.J. Griffin, The prediction of seat transmissibility from measures of seat impedance. Journal of Sound and Vibration 214 (1998) 121-137.

[20] L. Wei, C.H. Lewis, M.J. Griffin, Evaluating the dynamic performance of seat without using human subjects. ISVR Technical Report 296 (2000) 21-33.

[21] N. Nawayseh, M.J. Griffin, A model of the vertical apparent mass and the fore-and-aft cross-axis apparent mass of the human body during vertical whole-body vibration. Journal of Sound and Vibration 319 (2009) 719-730. 
Published as: Apparent mass of the human body in the vertical direction: Effect of seat backrest Toward, M. G. R. \& Griffin, M. J. 13 Nov 2009 In : Journal of Sound and Vibration. 327, 3-5, p. 657-669.

[22] Y. Cho, Y.S. Yoon, Biomechanical model of human on seat with backrest for evaluating ride quality, International Journal of Industrial Ergonomics 27 (2001) 331-345. 
Published as: Apparent mass of the human body in the vertical direction: Effect of seat backrest Toward, M. G. R. \& Griffin, M. J. 13 Nov 2009 In : Journal of Sound and Vibration. 327, 3-5, p. 657-669.

Table 1 Median resonance frequencies in the apparent mass moduli for the 23 backrest conditions.

\begin{tabular}{|c|c|c|c|c|c|}
\hline \multirow[t]{2}{*}{ Angle } & \multicolumn{5}{|c|}{ Frequency $(\mathrm{Hz})$} \\
\hline & No backrest & Rigid backrest & $\begin{array}{l}\text { 50-mm foam } \\
\text { backrest }\end{array}$ & $\begin{array}{c}100-\mathrm{mm} \text { foam } \\
\text { backrest }\end{array}$ & $\begin{array}{c}150-\mathrm{mm} \text { foam } \\
\text { backrest }\end{array}$ \\
\hline $0^{\circ}$ & 4.98 & 5.47 & 5.57 & 5.18 & 5.27 \\
\hline $5^{\circ}$ & & 5.47 & & 5.37 & \\
\hline $10^{\circ}$ & & 5.57 & 4.88 & 4.98 & 4.88 \\
\hline $15^{\circ}$ & & 6.25 & & 4.88 & \\
\hline $20^{\circ}$ & & 6.25 & 4.79 & 4.69 & 4.59 \\
\hline $25^{\circ}$ & & 5.76 & & 4.59 & \\
\hline $30^{\circ}$ & & 6.35 & 4.88 & 4.49 & 4.20 \\
\hline
\end{tabular}


Published as: Apparent mass of the human body in the vertical direction: Effect of seat backrest Toward, M. G. R. \& Griffin, M. J. 13 Nov 2009 In : Journal of Sound and Vibration. 327, 3-5, p. 657-669.

Table 2 Median apparent masses at the primary resonances for the 23 backrest conditions.

\begin{tabular}{|c|c|c|c|c|c|}
\hline \multirow[t]{2}{*}{ Angle } & \multicolumn{5}{|c|}{ Apparent mass (kg) } \\
\hline & No backrest & Rigid backrest & $\begin{array}{c}50-\mathrm{mm} \text { foam } \\
\text { backrest }\end{array}$ & $\begin{array}{c}100-\mathrm{mm} \text { foam } \\
\text { backrest }\end{array}$ & $\begin{array}{c}150-\mathrm{mm} \text { foam } \\
\text { backrest }\end{array}$ \\
\hline $0^{\circ}$ & 94.1 & 83.8 & 86.1 & 87.3 & 83.6 \\
\hline $5^{\circ}$ & & 82.0 & & 85.5 & \\
\hline $10^{\circ}$ & & 78.4 & 89.0 & 87.2 & 88.1 \\
\hline $15^{\circ}$ & & 76.3 & & 89.6 & \\
\hline $20^{\circ}$ & & 75.1 & 86.4 & 85.8 & 90.8 \\
\hline $25^{\circ}$ & & 73.2 & & 84.7 & \\
\hline $30^{\circ}$ & & 70.3 & 75.8 & 79.3 & 76.3 \\
\hline
\end{tabular}


Table 3 Effect of inclination of the rigid backrest: results of Wilcoxon matched-pairs signedranks tests and directions of change for differences in the apparent mass resonance frequency and apparent mass at resonance, at $0.4 \mathrm{~Hz}$, and at $12 \mathrm{~Hz}$.

\begin{tabular}{|c|c|c|c|c|c|c|c|}
\hline Backrest inclination, degrees & 0 & 5 & 10 & 15 & 20 & 25 & 30 \\
\hline \multicolumn{8}{|l|}{ (a) Resonance frequency } \\
\hline 0 & & ns - & $\mathrm{ns} \uparrow$ & $* \uparrow$ & $* \uparrow$ & ns $\uparrow$ & $* * \uparrow$ \\
\hline 5 & & & ns $\uparrow$ & ns $\uparrow$ & ns $\uparrow$ & ns $\uparrow$ & $* \uparrow$ \\
\hline 10 & & & & ns $\uparrow$ & $\mathrm{ns} \uparrow$ & ns $\uparrow$ & $* \uparrow$ \\
\hline 15 & & & & & $\mathrm{~ns} \uparrow$ & ns $\uparrow$ & ns $\uparrow$ \\
\hline 20 & & & & & & ns $\uparrow$ & ns $\uparrow$ \\
\hline 25 & & & & & & & $* \uparrow$ \\
\hline \multicolumn{8}{|l|}{30} \\
\hline \multicolumn{8}{|l|}{ (b) Apparent mass at resonance } \\
\hline 0 & & $\mathrm{~ns} \downarrow$ & ns $\downarrow$ & ns $\downarrow$ & $* \downarrow$ & $* \downarrow$ & $* * \downarrow$ \\
\hline 5 & & & * $\downarrow$ & $* * \downarrow$ & $* * \downarrow$ & ${ }^{* *} \downarrow$ & $* * \downarrow$ \\
\hline 10 & & & & ns $\downarrow$ & $* \downarrow$ & $* \downarrow$ & $* * \downarrow$ \\
\hline 15 & & & & & ns $\downarrow$ & ns $\downarrow$ & $* * \downarrow$ \\
\hline 20 & & & & & & $\mathrm{~ns} \downarrow$ & $* * \downarrow$ \\
\hline 25 & & & & & & & ${ }^{*} \downarrow$ \\
\hline \multicolumn{8}{|l|}{30} \\
\hline \multicolumn{8}{|l|}{ (c) Apparent mass at $0.4 \mathrm{~Hz}$} \\
\hline 0 & & $\mathrm{~ns} \uparrow$ & ns $\downarrow$ & ns $\uparrow$ & $* * \downarrow$ & ${ }^{* *} \downarrow$ & $* \star \downarrow$ \\
\hline 5 & & & ns $\uparrow$ & ${ }^{*} \downarrow$ & $* \downarrow$ & $* \downarrow$ & $* \star \downarrow$ \\
\hline 10 & & & & ns $\uparrow$ & $* \downarrow$ & $* \star \downarrow$ & $* * \downarrow$ \\
\hline 15 & & & & & $* * \downarrow$ & ${ }^{* *} \downarrow$ & $* * \downarrow$ \\
\hline 20 & & & & & & ${ }^{* *} \downarrow$ & $* * \downarrow$ \\
\hline 25 & & & & & & & $* * \downarrow$ \\
\hline \multicolumn{8}{|l|}{30} \\
\hline \multicolumn{8}{|l|}{ (d) Apparent mass at $12 \mathrm{~Hz}$} \\
\hline 0 & & $\mathrm{~ns} \uparrow$ & ns $\downarrow$ & ns $\downarrow$ & ns $\downarrow$ & $* \downarrow$ & $* \star \downarrow$ \\
\hline 5 & & & ns $\downarrow$ & ns $\downarrow$ & $\mathrm{ns} \downarrow$ & ${ }^{*} \downarrow$ & $* \star \downarrow$ \\
\hline 10 & & & & ns $\downarrow$ & ns $\downarrow$ & ${ }^{* *} \downarrow$ & $* \star \downarrow$ \\
\hline 15 & & & & & $\mathrm{~ns} \uparrow$ & $\mathrm{ns} \downarrow$ & $* \downarrow$ \\
\hline 20 & & & & & & ns $\downarrow$ & $* \downarrow$ \\
\hline 25 & & & & & & & ns $\downarrow$ \\
\hline 30 & & & & & & & \\
\hline
\end{tabular}

ns = not significant, $p>0.05 ;{ }^{*} p<0.05 ;{ }^{* *} p<0.01$.

$\uparrow$ median higher with greater backrest angle, $\downarrow$ median lower with greater backrest angle, - median same with both backrest angles. 
Table 4 Effect of inclination of the 100-mm foam backrest: results of Wilcoxon matched-pairs signed-ranks test and directions of change for differences in the apparent mass resonance frequency and apparent mass at resonance, at $0.4 \mathrm{~Hz}$ and at $12 \mathrm{~Hz}$.

\begin{tabular}{|c|c|c|c|c|c|c|c|}
\hline Backrest inclination, degrees & 0 & 5 & 10 & 15 & 20 & 25 & 30 \\
\hline \multicolumn{8}{|l|}{ (a) Resonance frequency } \\
\hline 0 & & $\mathrm{~ns} \uparrow$ & ns $\downarrow$ & ns $\downarrow$ & $\mathrm{ns} \downarrow$ & $* \downarrow$ & $* \downarrow$ \\
\hline 5 & & & * $\downarrow$ & $* \downarrow$ & $* * \downarrow$ & $* * \downarrow$ & $* * \downarrow$ \\
\hline 10 & & & & ns & ${ }^{*} \downarrow$ & $* * \downarrow$ & $* * \downarrow$ \\
\hline 15 & & & & & $\mathrm{~ns} \downarrow$ & $* \downarrow$ & $* \downarrow$ \\
\hline 20 & & & & & & ${ }^{*} \downarrow$ & $* \downarrow$ \\
\hline 25 & & & & & & & ns \\
\hline \multicolumn{8}{|l|}{30} \\
\hline \multicolumn{8}{|l|}{ (b) Apparent mass at resonance } \\
\hline 0 & & ns $\downarrow$ & ns $\downarrow$ & $\mathrm{ns} \uparrow$ & $\mathrm{ns} \downarrow$ & $\mathrm{ns} \downarrow$ & ns $\downarrow$ \\
\hline 5 & & & ns $\uparrow$ & ns $\uparrow$ & $\mathrm{ns} \uparrow$ & $\mathrm{ns} \downarrow$ & ns $\downarrow$ \\
\hline 10 & & & & ns $\uparrow$ & $\mathrm{ns} \downarrow$ & $\mathrm{ns} \downarrow$ & $* \downarrow$ \\
\hline 15 & & & & & $\mathrm{~ns} \downarrow$ & $* * \downarrow$ & $* * \downarrow$ \\
\hline 20 & & & & & & ${ }^{*} \downarrow$ & $* * \downarrow$ \\
\hline 25 & & & & & & & ns $\downarrow$ \\
\hline \multicolumn{8}{|l|}{30} \\
\hline \multicolumn{8}{|l|}{ (c) Apparent mass at $0.4 \mathrm{~Hz}$} \\
\hline 0 & & ns $\downarrow$ & ns - & $\mathrm{ns} \downarrow$ & $\mathrm{ns} \downarrow$ & $\mathrm{ns} \downarrow$ & $\mathrm{ns} \downarrow$ \\
\hline 5 & & & ns $\uparrow$ & $\mathrm{ns} \downarrow$ & $\mathrm{ns} \downarrow$ & $\mathrm{ns} \uparrow$ & $* \downarrow$ \\
\hline 10 & & & & ns $\downarrow$ & $\mathrm{ns} \downarrow$ & $\mathrm{ns} \downarrow$ & $\mathrm{ns} \downarrow$ \\
\hline 15 & & & & & $\mathrm{~ns} \uparrow$ & $\mathrm{ns} \uparrow$ & $* \downarrow$ \\
\hline 20 & & & & & & $\mathrm{~ns} \uparrow$ & $* * \downarrow$ \\
\hline 25 & & & & & & & $\mathrm{~ns} \downarrow$ \\
\hline \multicolumn{8}{|l|}{30} \\
\hline \multicolumn{8}{|l|}{ (d) Apparent mass at $12 \mathrm{~Hz}$} \\
\hline 0 & & ns - & ns $\downarrow$ & $* \downarrow$ & $* \downarrow$ & $* * \downarrow$ & $* * \downarrow$ \\
\hline 5 & & & ns $\downarrow$ & $* \downarrow$ & $* \downarrow$ & $* * \downarrow$ & $* * \downarrow$ \\
\hline 10 & & & & ns $\downarrow$ & $* \downarrow$ & $* * \downarrow$ & $* * \downarrow$ \\
\hline 15 & & & & & $\mathrm{~ns} \downarrow$ & $* \downarrow$ & $* \downarrow$ \\
\hline 20 & & & & & & $* \downarrow$ & $* * \downarrow$ \\
\hline 25 & & & & & & & ns $\downarrow$ \\
\hline 30 & & & & & & & \\
\hline
\end{tabular}

ns $=$ not significant, $p>0.05 ;{ }^{*} p<0.05 ;{ }^{* *} p<0.01$.

$\uparrow$ median higher with greater backrest angle, $\downarrow$ median lower with greater backrest angle, - median same with both backrest angles. 
Table 5 Statistically significant different (i.e. $p<0.05)$ pairs of backrest foam thicknesses with different backrest inclinations. 0: rigid backrest; 50: 50-mm foam backrest; 100: 100-mm foam backrest; 150: 150-mm foam backrest.

\begin{tabular}{|c|c|c|c|c|c|}
\hline & $\begin{array}{l}\text { Resonance } \\
\text { frequency }\end{array}$ & $\begin{array}{l}\text { Apparent } \\
\text { mass at } \\
\text { resonance }\end{array}$ & $\begin{array}{l}\text { Apparent } \\
\text { mass at } 0.4 \\
\mathrm{~Hz}\end{array}$ & $\begin{array}{l}\text { Apparent } \\
\text { mass at } 12 \\
\mathrm{~Hz}\end{array}$ & $\begin{array}{l}\text { Total out of } 24 \\
\text { possible } \\
\text { combinations }\end{array}$ \\
\hline \multirow[t]{3}{*}{ Backrest at $0^{\circ}$} & & & & $0 / 50 \downarrow$ & 3 \\
\hline & & & & $0 / 100 \downarrow$ & \\
\hline & & & & $0 / 150 \downarrow$ & \\
\hline \multirow[t]{3}{*}{ Backrest at $10^{\circ}$} & & & & $0 / 50 \downarrow$ & 3 \\
\hline & & & & $0 / 100 \downarrow$ & \\
\hline & & & & $0 / 150 \downarrow$ & \\
\hline \multirow[t]{4}{*}{ Backrest at $20^{\circ}$} & $0 / 50 \downarrow$ & $0 / 50 \uparrow$ & $0 / 100 \uparrow$ & $0 / 50 \downarrow$ & 14 \\
\hline & $0 / 100 \downarrow$ & $0 / 100 \uparrow$ & $0 / 150 \uparrow$ & $0 / 100 \downarrow$ & \\
\hline & $0 / 150 \downarrow$ & $0 / 150 \uparrow$ & $50 / 100 \uparrow$ & $0 / 150 \downarrow$ & \\
\hline & $100 / 150 \downarrow$ & & $50 / 150 \uparrow$ & & \\
\hline \multirow[t]{5}{*}{ Backrest at $30^{\circ}$} & $0 / 50 \downarrow$ & $0 / 50 \uparrow$ & $0 / 50 \uparrow$ & $0 / 50 \downarrow$ & 18 \\
\hline & $0 / 100 \downarrow$ & $0 / 100 \uparrow$ & $0 / 100 \uparrow$ & $0 / 100 \downarrow$ & \\
\hline & $0 / 150 \downarrow$ & $0 / 150 \uparrow$ & $0 / 150 \uparrow$ & $0 / 150 \downarrow$ & \\
\hline & $50 / 100 \downarrow$ & & $50 / 100 \uparrow$ & $50 / 100 \downarrow$ & \\
\hline & $50 / 150 \downarrow$ & & $50 / 150 \uparrow$ & $50 / 150 \downarrow$ & \\
\hline
\end{tabular}

Comparisons shown where $p<0.05$; Wilcoxon matched-pairs signed ranks test.

$\uparrow$ median higher with greater foam thickness, $\downarrow$ median lower with greater foam thickness. 
Table 6 Statistically significant different (i.e. $p<0.05$ ) pairs of backrest inclinations with different thickness of foam backrest. 0: upright backrest; 10: backrest reclined to $10^{\circ} ; 20$ : backrest reclined to $20^{\circ} ; 30$ : backrest reclined to $30^{\circ}$.

\begin{tabular}{|c|c|c|c|c|c|}
\hline & $\begin{array}{l}\text { Resonance } \\
\text { frequency }\end{array}$ & $\begin{array}{l}\text { Apparent mass at } \\
\text { resonance }\end{array}$ & $\begin{array}{l}\text { Apparent } \\
\text { mass at } \\
0.4 \mathrm{~Hz}\end{array}$ & $\begin{array}{l}\text { Apparent } \\
\text { mass at } \\
12 \mathrm{~Hz}\end{array}$ & $\begin{array}{l}\text { Total out of } \\
24 \text { possible } \\
\text { combinations }\end{array}$ \\
\hline \multirow[t]{5}{*}{ Rigid backrest } & $0 / 20 \uparrow$ & $0 / 20 \downarrow$ & $0 / 20 \downarrow$ & $0 / 30 \downarrow$ & 16 \\
\hline & $0 / 30 \uparrow$ & $0 / 30 \downarrow$ & $0 / 30 \downarrow$ & $10 / 30 \downarrow$ & \\
\hline & $10 / 30 \uparrow$ & $10 / 20 \downarrow$ & $10 / 20 \downarrow$ & $20 / 30 \downarrow$ & \\
\hline & & $10 / 30 \downarrow$ & $10 / 30 \downarrow$ & & \\
\hline & & $20 / 30 \downarrow$ & $20 / 30 \downarrow$ & & \\
\hline \multirow[t]{4}{*}{$50 \mathrm{~mm}$ foam } & $0 / 20 \downarrow$ & $0 / 30 \downarrow$ & $0 / 30 \downarrow$ & $0 / 20 \downarrow$ & 12 \\
\hline & & $10 / 30 \downarrow$ & $10 / 20 \downarrow$ & $0 / 30 \downarrow$ & \\
\hline & & $20 / 30 \downarrow$ & $10 / 30 \downarrow$ & $10 / 20 \downarrow$ & \\
\hline & & & $20 / 30 \downarrow$ & $10 / 30 \downarrow$ & \\
\hline \multirow[t]{5}{*}{$100 \mathrm{~mm}$ foam } & $0 / 30 \downarrow$ & $10 / 30 \downarrow$ & $20 / 30 \downarrow$ & $0 / 20 \downarrow$ & 12 \\
\hline & $10 / 20 \downarrow$ & $20 / 30 \downarrow$ & & $0 / 30 \downarrow$ & \\
\hline & $10 / 30 \downarrow$ & & & $10 / 20 \downarrow$ & \\
\hline & $20 / 30 \downarrow$ & & & $10 / 30 \downarrow$ & \\
\hline & & & & $20 / 30 \downarrow$ & \\
\hline \multirow[t]{5}{*}{$150 \mathrm{~mm}$ foam } & $0 / 10 \downarrow$ & $10 / 30 \downarrow$ & $0 / 30 \downarrow$ & $0 / 20 \downarrow$ & 15 \\
\hline & $0 / 20 \downarrow$ & $20 / 30 \downarrow$ & $10 / 30 \downarrow$ & $0 / 30 \downarrow$ & \\
\hline & $0 / 30 \downarrow$ & & $20 / 30 \downarrow$ & $10 / 20 \downarrow$ & \\
\hline & $10 / 30 \downarrow$ & & & $10 / 30 \downarrow$ & \\
\hline & $20 / 30 \downarrow$ & & & $20 / 30 \downarrow$ & \\
\hline
\end{tabular}

Comparisons shown where $p<0.05$; Wilcoxon matched-pairs signed ranks test.

$\uparrow$ median higher with greater backrest angle, $\downarrow$ median lower with greater backrest angle. 
Published as: Apparent mass of the human body in the vertical direction: Effect of seat backrest Toward, M. G. R. \& Griffin, M. J. 13 Nov 2009 In : Journal of Sound and Vibration. 327, 3-5, p. 657-669.

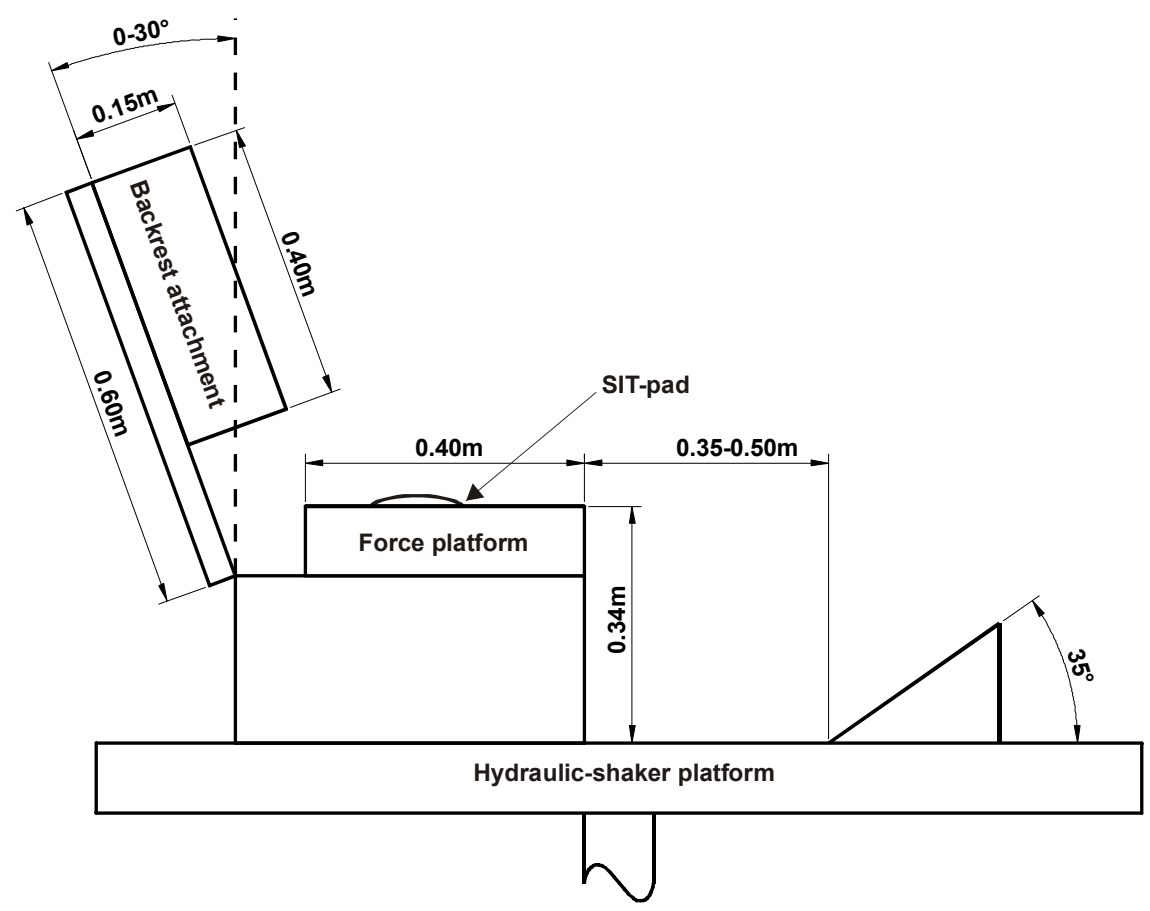

Fig. 1 General arrangement of the seat, footrest, and transducers on the vibrator platform. 

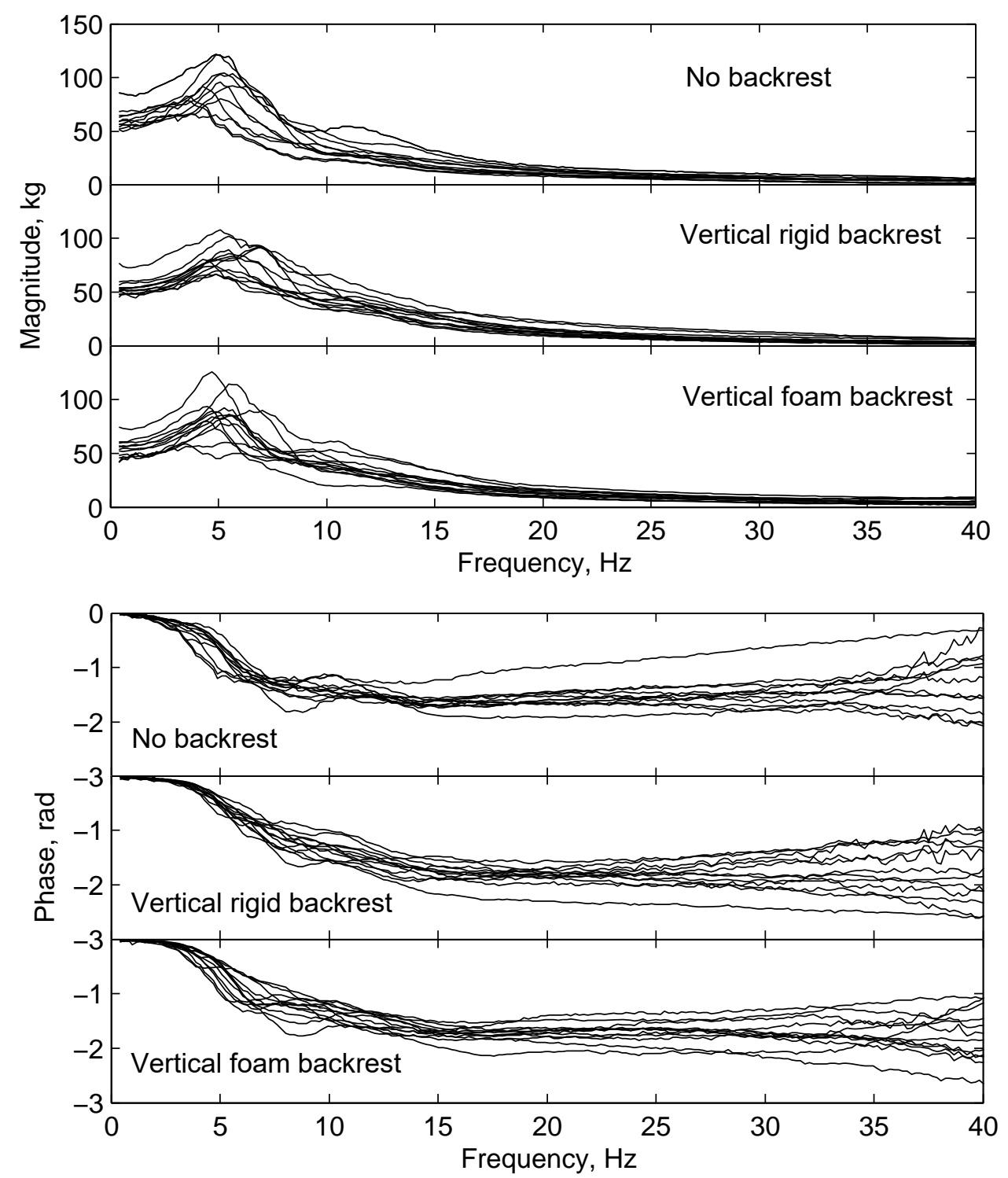

Fig. 2 Moduli and phases of the vertical apparent masses of the 12 subjects with no backrest, a vertical rigid backrest, and a vertical foam $(100 \mathrm{~mm})$ backrest. 


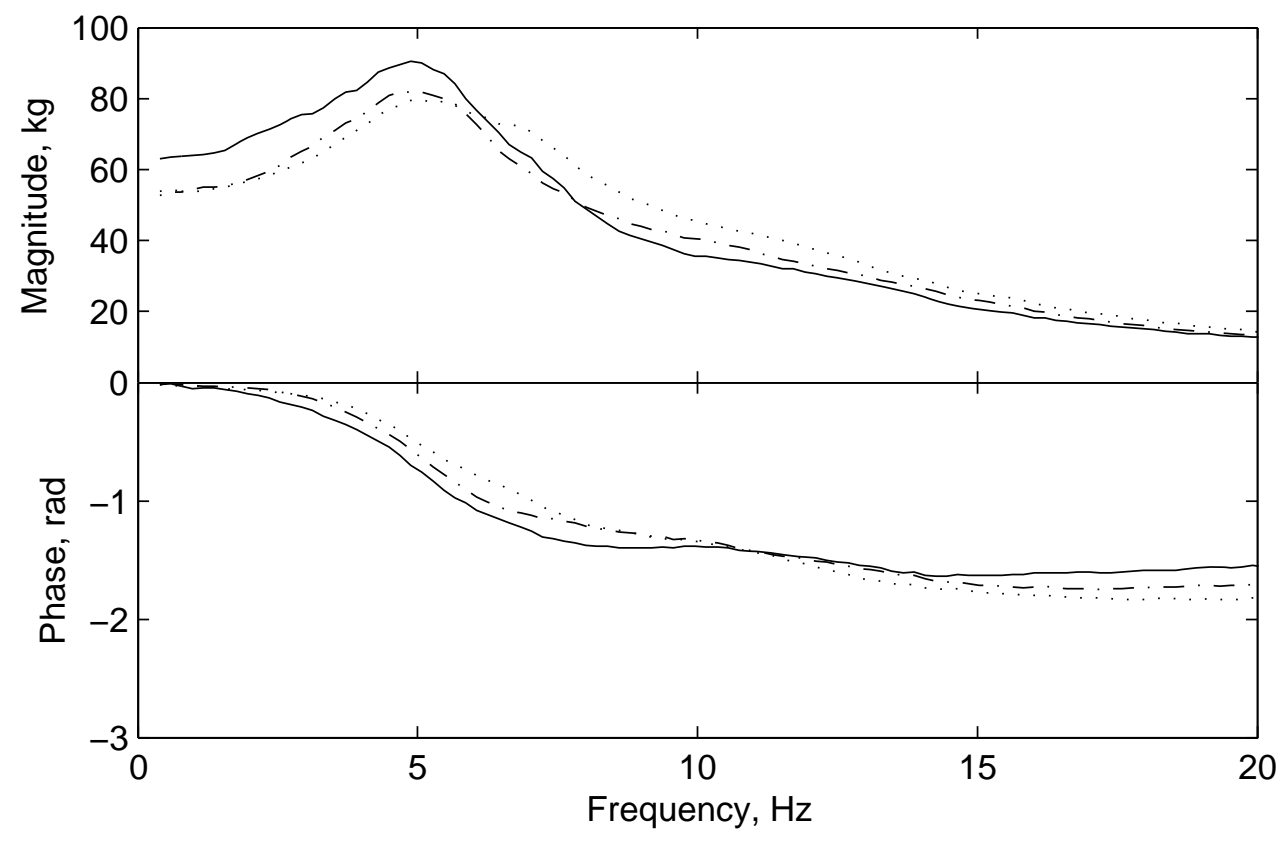

Fig. 3 Effect of backrest contact and backrest type on the modulus and phase of the median apparent mass (median vertical apparent mass of 12 subjects measured on the seat): , no backrest; $\quad \cdots \cdots$, , rigid backrest at $0^{\circ} ; \cdots \cdots, 100-\mathrm{mm}$ foam backrest at $0^{\circ}$. 


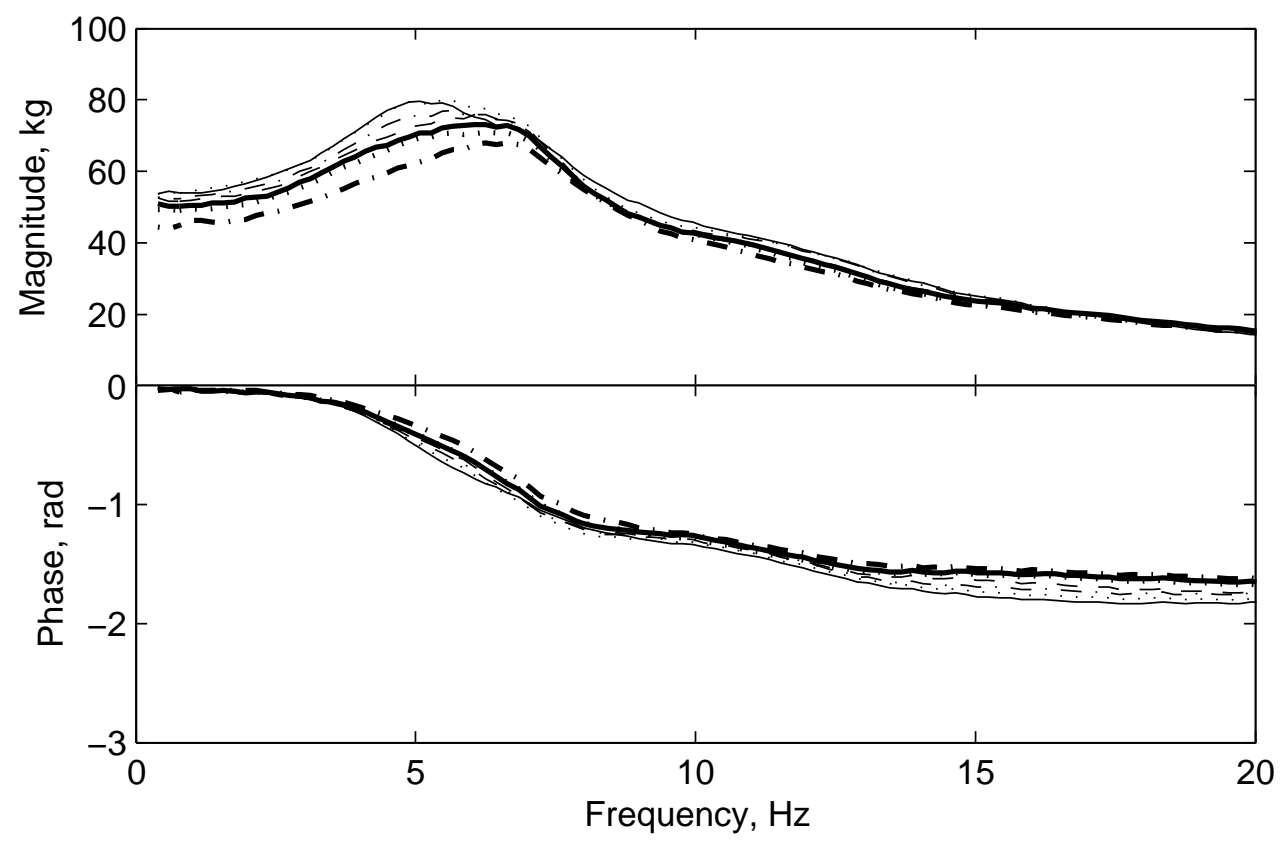

Fig. 4 Effect of inclination of a rigid backrest on the median vertical apparent masses of 12 subjects measured on the seat:,$- 0^{\circ} ; \cdots, 5^{\circ} ; \cdots \cdots 10^{\circ} ; \cdots, 15^{\circ}$; , $20^{\circ} ; \cdot \cdots, 25^{\circ} ; \cdot-\cdot-\cdot 30^{\circ}$. 


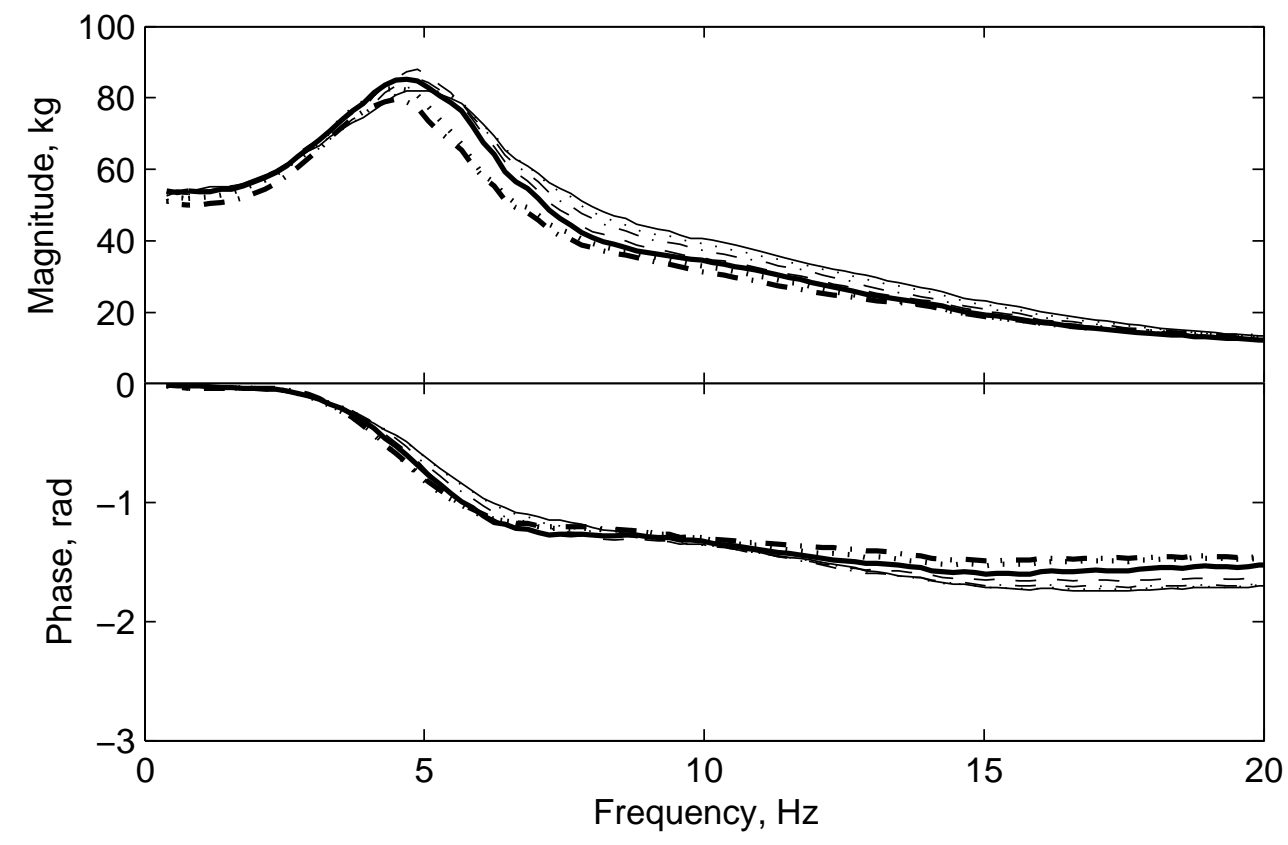

Fig. 5 Effect of inclination of a $100-\mathrm{mm}$ foam backrest on the median vertical apparent masses of 12 subjects measured on the seat:,$- 0^{\circ} ; \cdots \cdots, 5^{\circ} ; \cdots \cdots 10^{\circ} ; \cdots$ , $15^{\circ} ;$

, $20^{\circ} ; \cdot \cdots \cdot 25^{\circ}$ ,$- 30^{\circ}$. 

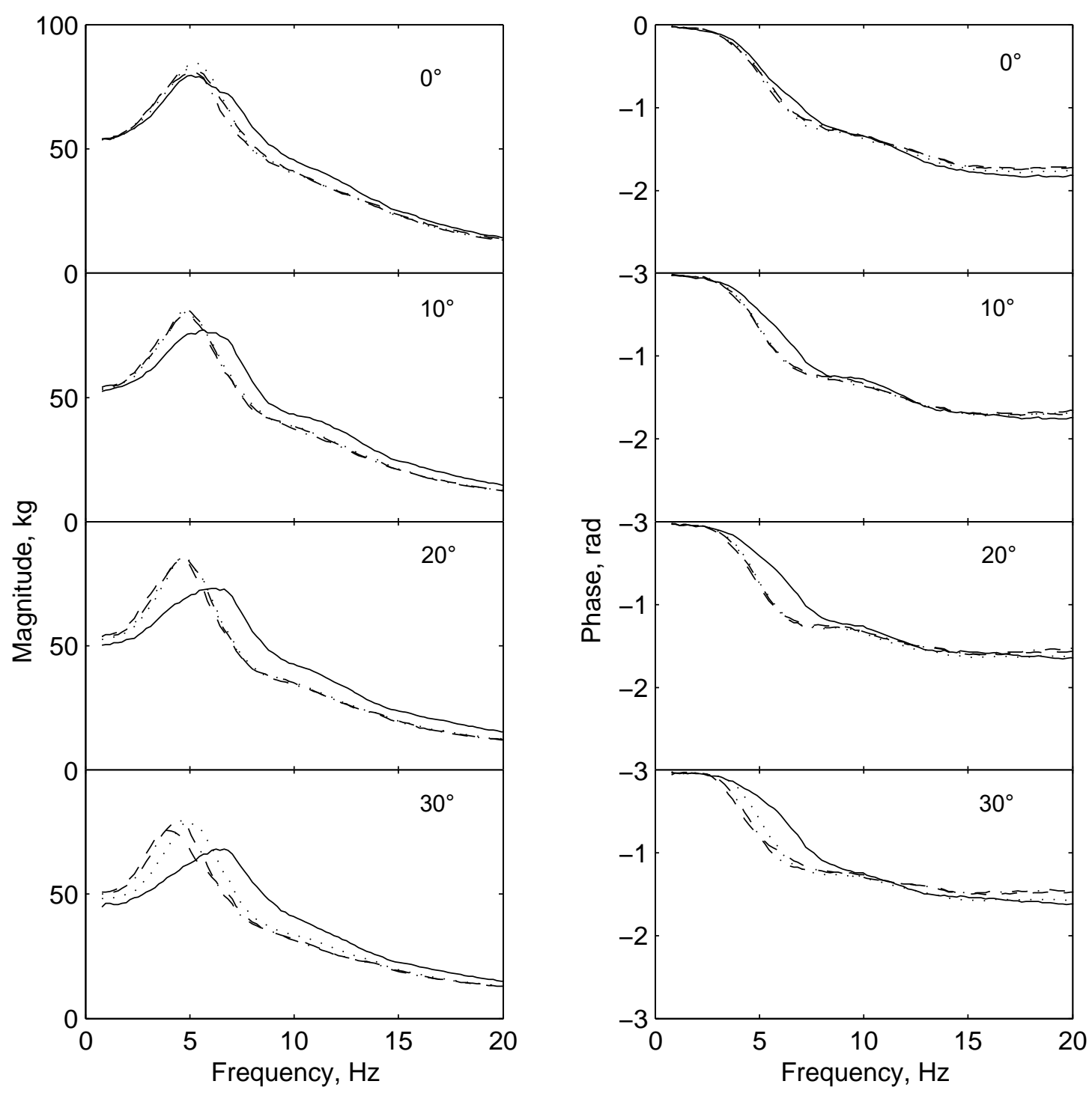

Fig. 6 Effect of backrest foam thickness at different backrest inclinations on the median vertical apparent masses of 12 subjects measured on the seat: , rigid backrest; ....., 50-mm foam; . . - . - 100-mm foam; - - - - , 150-mm foam. 

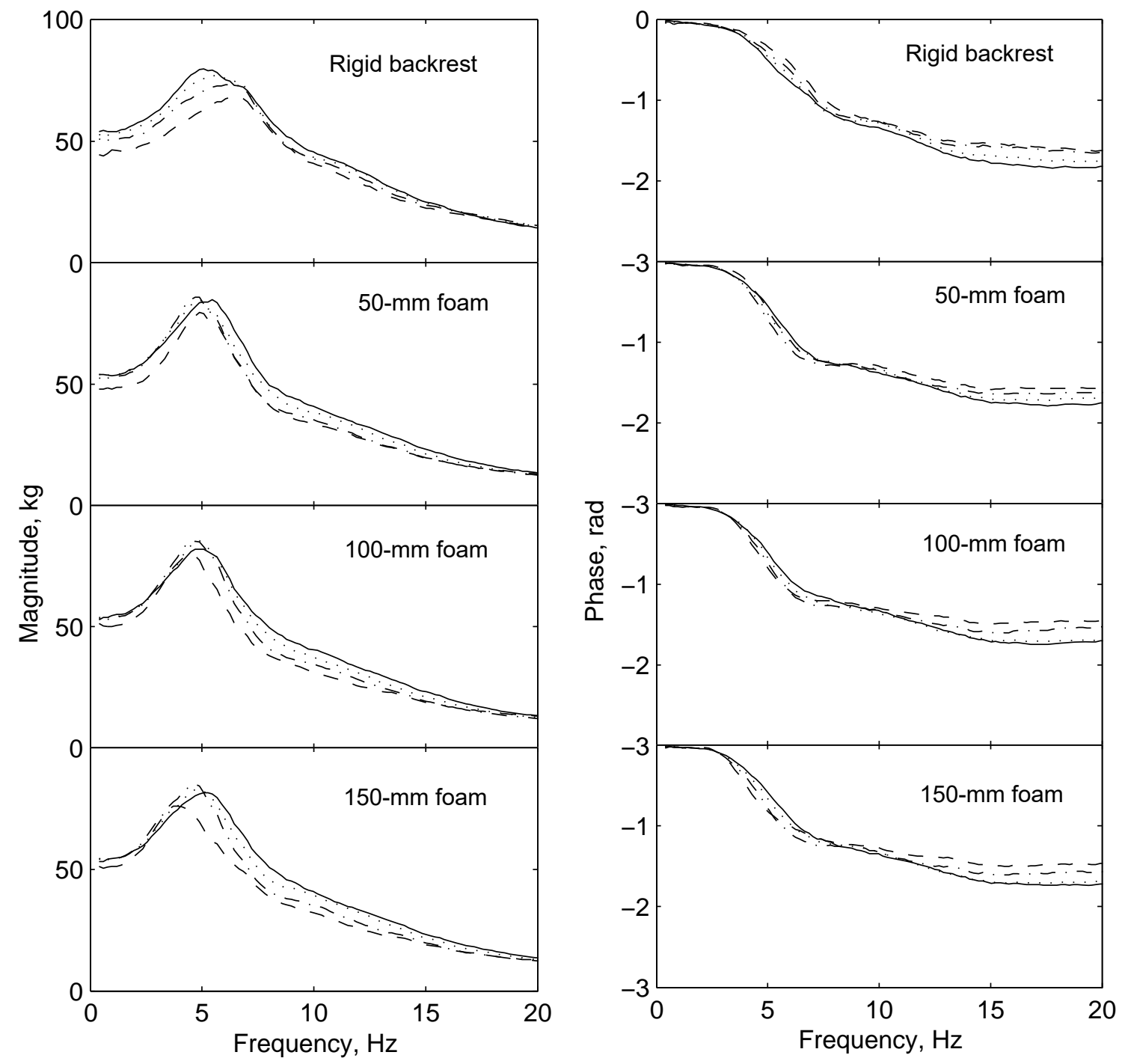

Fig. 7 Effect of backrest inclination with different thicknesses of foam backrest on the median vertical apparent masses of 12 subjects measured on the seat: , $0^{\circ} ; \cdots, 10^{\circ}$ - $20^{\circ} ;--.-2,30^{\circ}$. 